\title{
The Effects of Government Regulations on the Supply of Pawn Loans: Evidence from 51 Jurisdictions in the U.S.
}

\author{
Joshua D. Shackman • Glen Tenney \\ (C) Springer Science + Business Media, LLC 2006
}

\begin{abstract}
In the online and printed version of this article, and in the XML file, the corresponding author's email address is listed incorrectly. Glen Tenney's correct e-mail address is tenney@gbcnv.edu.
\end{abstract}

The online version of the original article can be found at: http://dx.doi.org/10.1007/s10693-006-8740-5

J. D. Shackman

Touro University International, Cypress, CA 90630, USA

G. Tenney $(\bowtie)$

Great Basin College, 1500 College Parkway, Elko, NV 89801, USA

e-mail: tenney@gbcnv.edu 